\title{
Gastric primary non-Hodgkin lymphoma: a case report and literature review
}

${ }^{1}$ Clinical Service of Pathology, Emergency County Hospital, Constanta

${ }^{2}$.Department of Pathology, Faculty of Medicine, „Ovidius” University, Constanta

\begin{abstract}
Non-Hodgkin malignant lymphomas represent a heterogeneous group of monoclonal tumors developing from cells belonging to the immune system. Primary gastric lymphomas are defined as those malignant limphoproliferative diseases whose initial symptoms are located in the stomach or tumor mass located in the stomach. This paper aims to present a new case of primary gastric non Hodgkin lymphoma diagnosed by histologic and immunohistochemical examination of a partial gastrectomy specimen. The patient is a 51-years old man with a history of smoking, hospitalized for asthenia, hematemesis and melena. Microscopically the tumor consisted of mature small lymphocytes admixed with plasmocitoid lymphocytes and mature plasmocytes. Some of the tumoral cells showed citoplasmatic pas positive inclusions. Immunohistochemical stains were strongly positive for CD20 and $30-40 \%$ positive for Ki67.Based on the clinical and histological findings, a diagnosis of gastric primary non-Hodgkin lymphoma was established.
\end{abstract}

Key words: primary non-Hodgkin lymphoma, stomach, CD20, Ki67, lymphocyte

Mariana Aschie

Department of Pathology, Faculty of Medicine, "University "Ovidius" Constanța

Clinical Service of Pathology, Emergency County Hospital

145 Tomis Avenue, 900591 Constanţa, Romania

$+40745043505$

aschiemariana@yahoo.com

\section{Introduction}

Non-Hodgkin's malignant lymphomas are malignant proliferations of the cells belonging to the immune system. These limphoproliferative diseases usually start and affect the lymphoid organs, but even if not with the same frequency, they can start in and affect any organ or tissue where these cells are present. They can begin outside lymph nodes, even in organs that don't have their own lymphatic tissue - such as the stomach that contains only a reduced number of B-lymphocytes on the IgM surface. Gastric lymphoma is considered to be a primary neoplasm when the initial symptoms of disease are located in the stomach or when the tumor mass is located in the stomach. [1]The gastrointestinal tract appears to be a common location of non-Hodgkin lymphomas with extranodal onset (30-40\% of extranodal cases), but comparing it with all non-Hodgkin lymphomas, primary gastric disease represents only $4-20 \%$ of all cases of malignant non-Hodgkin lymphomas $[1,2]$. But we should not forget to mention that even if - as stated above - the stomach does not have its own lymphatic tissue, non-Hogdkin malignant lymphoma is recognized as being the most frequent gastric malignancy after adenocarcinomas. On the contrary, the involvement of the stomach in Hodgkin 
lymphoma is quite rare, regardless of it being a primary or secondary involvement $[1,3]$.

\section{Patient, Methods and Results}

We present the case of a male patient, 51-yearold, with a history of smoking, who presented asthenia, hematemesis and melena. The patient admitted to smoking about 50 cigarettes a day for many years and he was also an occasional drinker. Laboratory tests showed decreased hematocrit and hemoglobin levels and increased values for urea. The number of red blood cells was also low. During the following days, although the patient was under medication, these lab values continued to vary, but never reached normal range. An upper gastrointestinal endoscopy was performed in the Department of Gastroenterology of the Emergency County Hospital of Constanta. The result showed a gastric ulcerated lesion with the presence of digested blood in the stomach. The case was declared above the endoscopic resources so, the patient was hospitalized and he underwent a partial gastrectomy. The excised material was processed by the Clinical Service of Pathology, Emergency County Hospital of Constanta. The specimen was fixed in $10 \%$ formalin and paraffin-embedded. The sections were first stained with Hematoxylin-Eosin and then microscopic images were taken with a Nikon camera using a Nikon Eclipse E600 Microscope. Macroscopic examination revealed the presence of multiple fragments with variable diameters, which measured overall 5.5/2/0.5 cm, with medium consistency. One of the surfaces was slightly irregular, light-reddish hemorrhagic spotting, while the other surface was light yellowish. On the routine stain (H\&E), as well as on the Van Gieson stain (Figure 1), histopathological examination revealed a malignant neoplastic proliferation with polymorphic lymphoid cells - a mixture of mature small lymphocytes, plasmocitoid lymphocytes and mature plasmocytes (Figure 2). Some of the neoplastic cells showed acidophilic cytoplasmatic inclusions. The tumor cells invaded the mucosa reaching the submucosal tissue, but mitoses were quite rare (Figure 3). The muscular tissue and the serosa seemed to be slightly hyperemic. Even so, the distal surgical margin showed the presence of some lymphoid neoplastic cells. We considered that an evaluation by immunohistochemical techniques was mandatory.

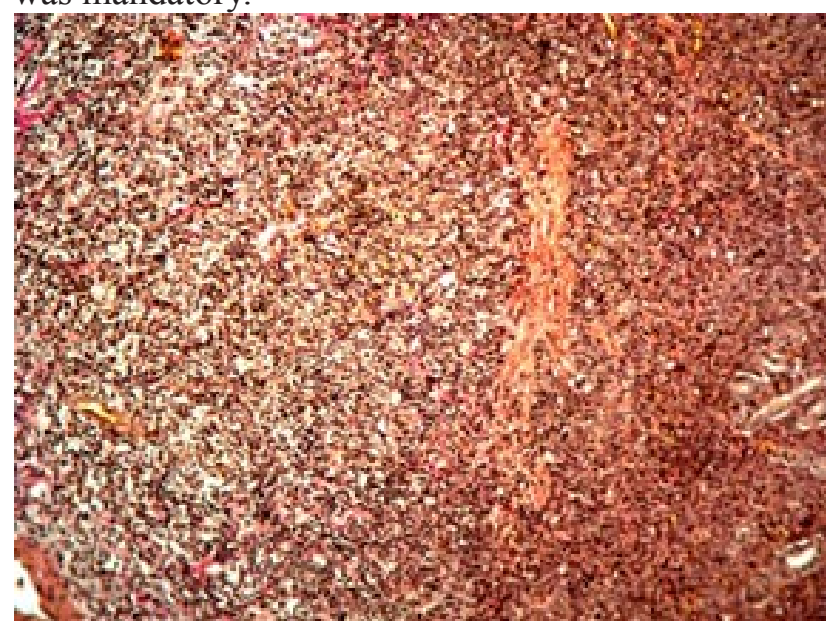

Figure 1 - Malignant neoplastic proliferation with polymorphic lymphoid cells (VG stain, 10×)

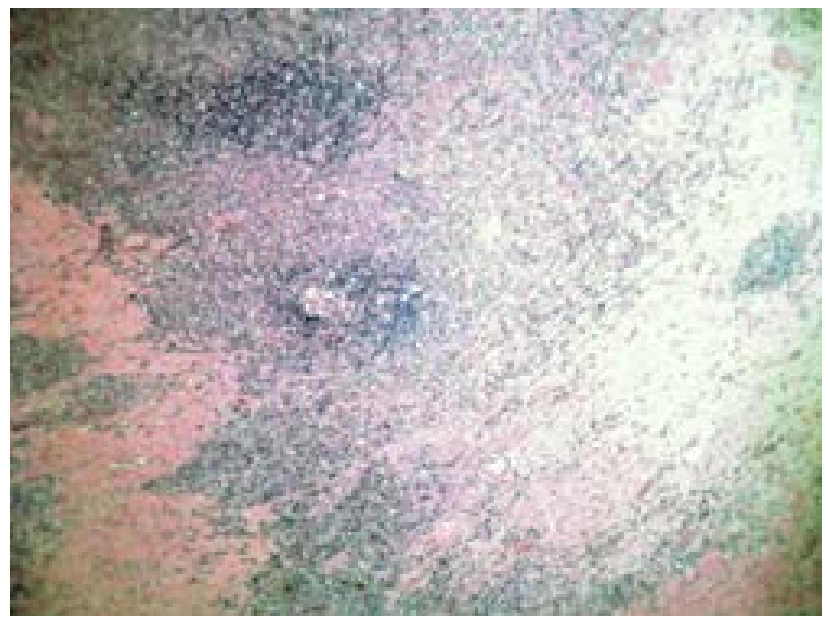

Figure 2-Malignant neoplastic proliferation with polymorphic lymphoid cells - a mixture of mature small lymphocytes, plasmocitoid lymphocytes and mature plasmocytes (HE stain, $5 x$ )

Immunohistochemical stains for Ki67, CD20, $\mathrm{CD} 79 \mathrm{a}$ and $\mathrm{CD} 3$ revealed the following aspects:

- Strong membranal positivity for CD20 (Figure 4)

- 30-40\% nuclear positivity for Ki67 (Figure 
5)

- Membranal and cytoplasmatic positivity for CD79a (Figure 6)

- Positivity for CD3 but only in the reactive lymphocytes (Figure 7)

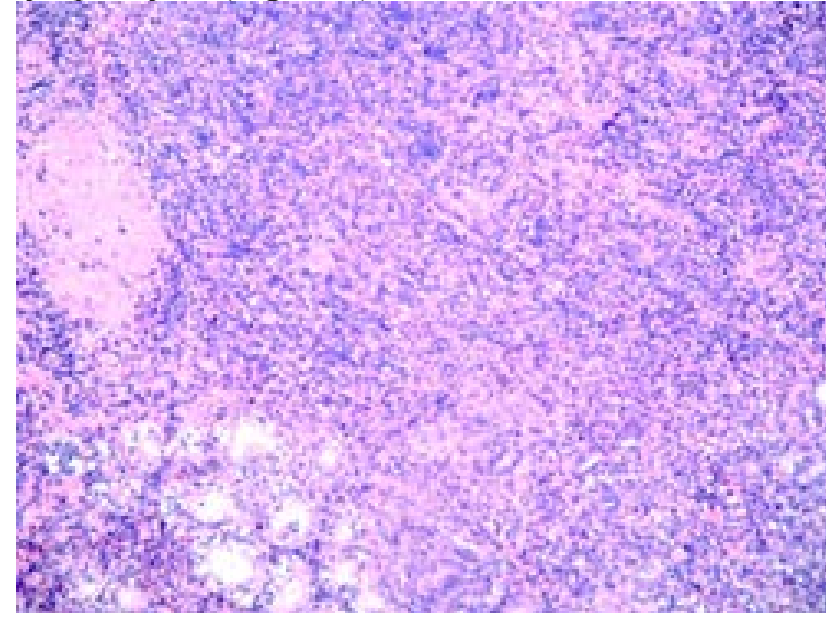

Figure 3 - Tumor cells invaded the mucosa reaching the submucosal tissue, but mitoses were quite rare (HE stain,

$5 x)$

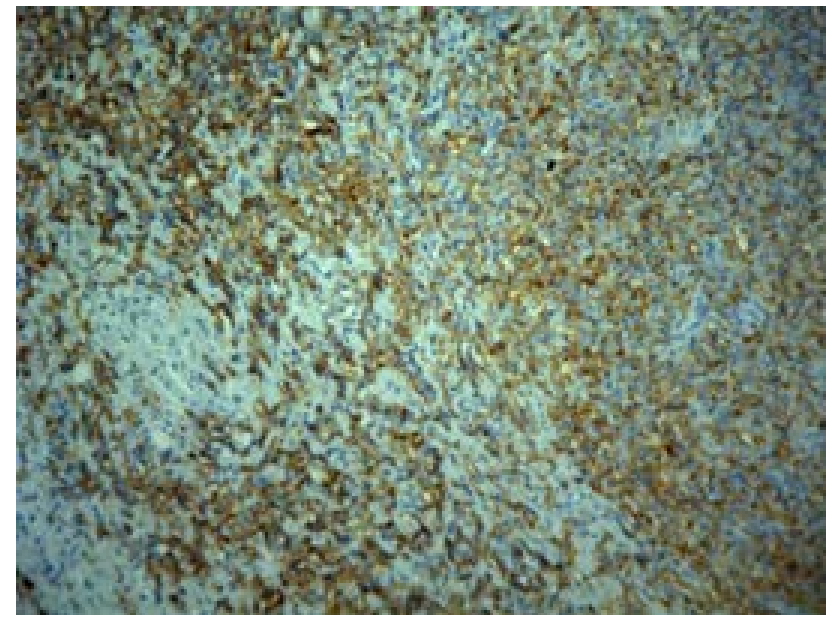

Figure 4 - Strong membranal positivity for CD20 (CD20 staining, 20x)

CD20 is expressed during all developmental stages of the B lymphocyte, with the exception of the first and the last stage. The antibodies for CD3 antigen recognize the T cells - wherever they appear: thymus, bone marrow, peripheral lymphoid tissue and blood - detecting the neoplastic T lymphocytes as well as the normal $\mathrm{T}$ lymphocytes. CD79a gets identified in B-cell lines and B-cell lymphomas, but also in some multiple myelomas and in almost all acute leukemia cases. Ki67 is a protein involved in cellular proliferation and illustrates the proliferation rates.

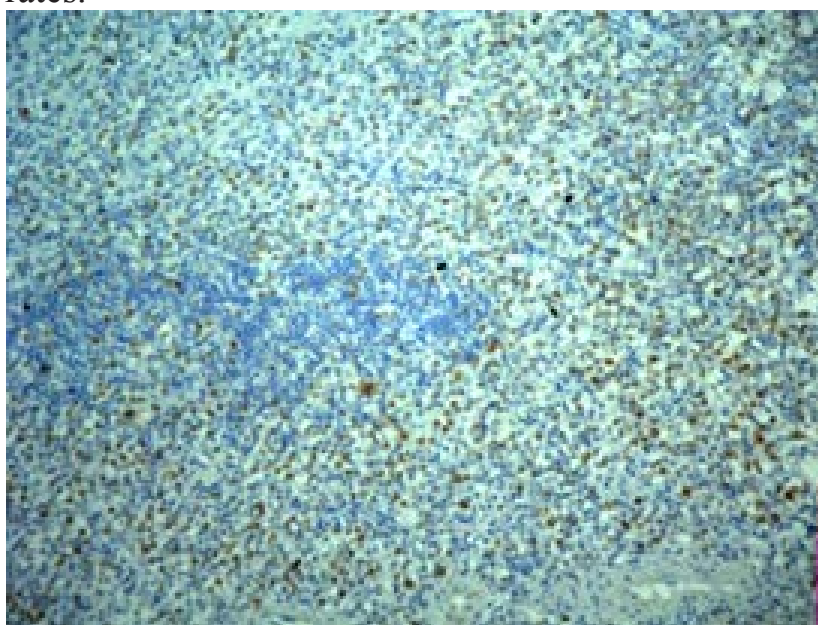

Figure 5-Nuclear positivity for Ki67 (Ki67 staining, 10x)

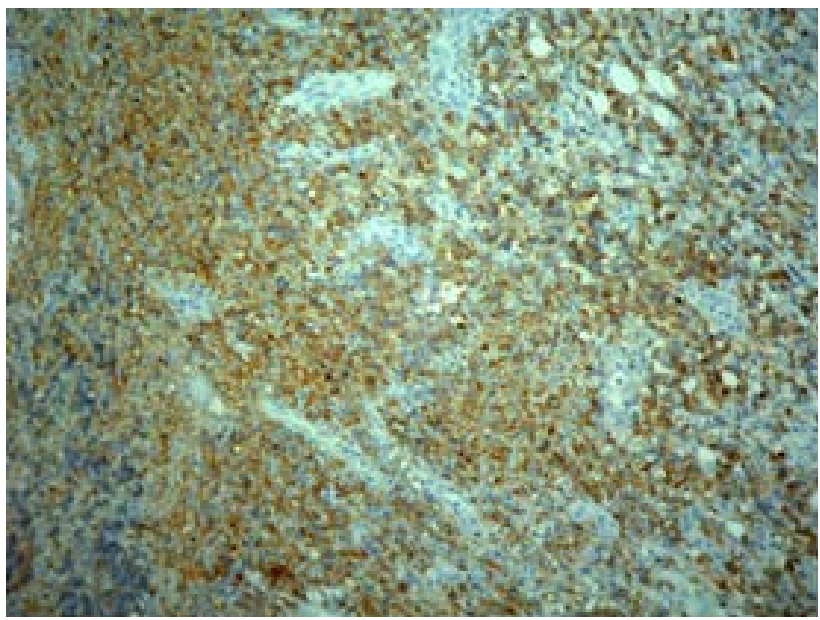

Figure 6 - Membranal and cytoplasmatic positivity for CD79a (CD79a staining, 10x)

The characteristic features of immunohistochemical reactions lead to the final diagnosis of malignant gastric non-Hodgkin B-cell lymphoma, lymphoplasmocitoid form. 


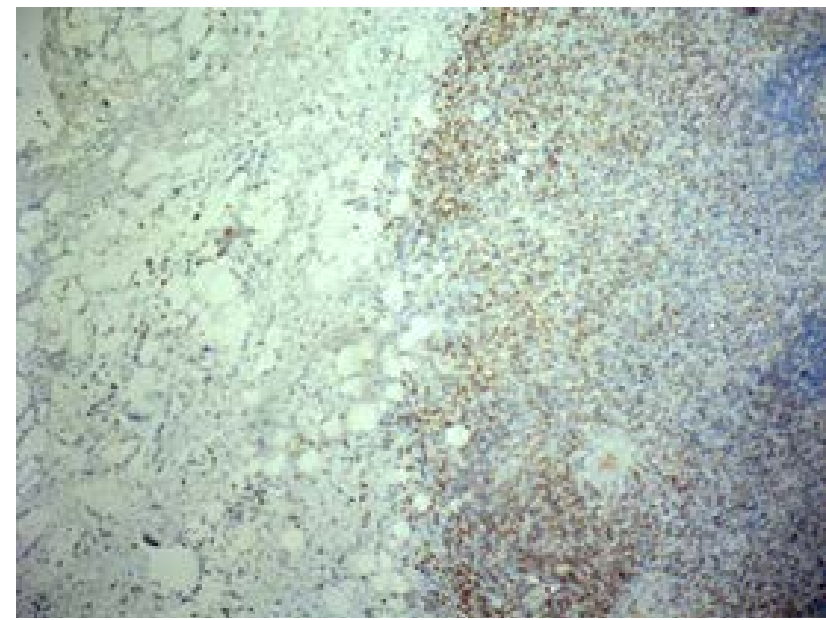

Figure 7 - Positivity for CD3 but only in the reactive lymphocytes (CD3 staining, 5x)

\section{Discussion}

Primary gastric diffuse large B-cell lymphoma is defined as a malignancy composed of large cells, with prominent nucleoli and basophilic cytoplasm [1]. From this point of view, the present case showed smaller cells, as described above, but Bartl et all described three morphological variants of the lymphoplasmocytic lymphoma: the lymphoplasmocitoid, lymphocytic and polymorphic forms. In the lymphoplasmocitoid subtype the cells resemble small lymphocytes, occasionally presenting plasmocitoid lymphocytes and rare mature plasmocytes $[5,6,7]$. These findings are consistent with our findings in this case.

Although non-Hodgkin lymphoma usually displays a nodal beginning, the extranodal onset appears to be more frequent compared to Hodgkin lymphomas $[1,8]$. The digestive system can be involved form the beginning of the disease - just like in our case - or can get affected during the later development. The digestive primary lymphomas represent $5-6 \%$ of all patients.

In order to have a proper management of this disease, it is very important to make a very accurate differential diagnosis. We have to differentiate non-Hodgkin lymphoma from other lymphoproliferative diseases such as Hodgkin lymphoma, Waldenstrom disease, hairy cell leukemia and other forms of leukemia[9]. Sometimes, in order to get the exact diagnosis it is indispensable to use immunophenotyping, immunohistochemical or cytogenetic techniques, which also happened in our case.

The literature shows that the proliferation index is usually moderate to high, which is also consistent with our findings - Ki67 appeared to be $30-40 \%$ positive [10]. The low malignancy histological forms usually evolve to fast generalization, but show a 6-7 years of indolent evolution. The high malignancy forms have a more severe prognosis, that get even worse when autoimmune complications appear.

As with all other diffuse large cell B-lymphomas, the cells of primary gastric lymphoma express B-cell associated antigens (CD20, CD79a, etc.) $[1,11]$.

Regarding the laboratory investigations, the $\mathrm{CBC}$ is usually within normal range at the beginning of the disease or in the localized forms. Sometimes, the hemoglobin can be lowered if we have associated bleeding - usually digestive bleeding [12].

The positive diagnostic will be sustained by corroborating the clinical and the paraclinical information, but the confirmation always comes after the histopathological exam.

\section{Conclusions}

Primary gastric non-Hodgkin lymphomas are not very frequent, but still not very rare. In our case, the patient presented with digestive acute bleeding which oriented the primary diagnosis to a perforated ulceration. But, the histopathological examination showed that the real cause was a non-Hodgkin lymphoma. Generally speaking, the diagnose of lymphomas is based on histopathological 
examination and immunohistochemical stains, but in order to diagnose a primary non-Hodgkin lymphoma, other possible limphoproliferative diseases have to be excluded. Also, the histopathological examination as well as the other special techniques makes possible the characterization of the histological subtype, which is very important for the future management of the patient.

\section{References}

1. Rotaru, I., Ciurea, T., Foarfa, C., Tanase, A.D. \& Gaman, G. (2012). The diagnostic characteristics of a group of patients with primary gastric lymphoma: macroscopic, histopathological and immunohistochemical aspects. RJME. 53(2), 343-350

2. D'Amore, F., Christensen, B.E., Thorling, K., Pedersen, M., Jensen, M.K., Boesen, A.M., Andersen, E., Johansen, P. \& Mortensen, L.S. (1993). Incidence, presenting features and prognosis of low-grade B-cell non-Hodgkin's lymphomas. Population base data from a Danish lymphoma registry. Leuk Lymphoma. 12(1-2), 69-77

3. Venizelos, I., Tamiolakis, D., Bolioti, S., Nikolaidou, S., Lambropoulou, M., Alexiadis, G., Manavis, J. \& Papadopoulos, N. (2005). Primary gastric Hodgkin's lymphoma: a case report and review of the literature. Leuk Lymphoma. 46(1), 147-150

4. Gurney, K.A., Cartwright, R.A. \& Gilman, E.A. (1999). Descriptive epidemiology of gastrointestinal non-Hodgkin's lymphoma in a population-based registry. $\mathrm{Br} J$ Cancer. 79(1112), 1929-1934

5. Lin, P., Bueso-Ramos, C. \& Wilson, C.S. et al. (2003). Waldenstrom macroglobulinemia involving extramedullary sites: Morphologic and immunophenotypic findings in 44 patients. $\mathrm{Am} \mathrm{J}$ Surg Pathol. 27, 1104-1113

6. Alexanian, R., Weber, D. \& Delasalle, K. et al. (2003). Asymptomatic Waldenstrom's macroglobulinemia. Semin Oncol. 30, 206-210

7. Așchie, M. (2011). Limfoame Maligne NonHodgkiniene Gastrointestinale - Entitati Anatomo-Clinice si Morfologice (pp. 116-121). București: Editura Academia de Stiinte Medicale

8. Chubachi, A., Miura, A.B. \& Takatsu, H. et al. (1991). Clinical significance of immunophenotype in diffuses non Hodgkin's lymphoma, with special emphasis on the clinical characteristic of $\mathrm{T}$ cell lymphoma, Gan To Kagaku Ryoho. 18(8), 1303-1309

9. Biemer, J.J. (1984). Hepatic manifestations of lymphomas. Annals of Clinical and Laboratory Science. 14(4), 252-260

10. Harris, N.L., Jaffe, E.S., Diebold, J., Flandrin, G., Muller-Hermelink, H.K., Vardiman, J., Lister, T.A. \& Bloomfield, C.D. (1999). World Health Organization classification of neoplastic diseases of the hematopoietic and lymphoid tissues: report of the Clinical Advisory Committee meeting Airlie House, Virginia, November 1997. J Clin Oncol. 17(12), 3835-3849

11. Ponzoni, M., Ferreri, A.J., Pruneri, G., Pozzi, B., Dell'Oro, S., Pigni, A., Pinotti, G., Villa, E., Freschi, M., Viale, G. \& Capella, C. (2003). Prognostic value of bcl-6, CD10 and CD38 immunoreactivity in stage I-II gastric lymphomas: identification of a subset of $\mathrm{CD} 10+$ large B-cell lymphomas with a favorable outcome, Int J Cancer. 106(2), 288-291

12. Conde, G.J. \& Cabanillas, F. (1994). Mantie cell lymphoma, a new lymphoproliferafive entity with definite histopathological patterns, clinical characteristic and prognostic factors, and an investitional therapeutic approach. Journal of Clinical Oncology. 14 (2), 279 - 286 